\title{
Applications of Non-Linear Controllers for Improving Distribution Networks Performances
}

\author{
Abdul-Jabbar Fathel Ali \\ A. Prof. Dr. Eng. Wasit/University
}

\begin{abstract}
Power quality is a problem that leads to financial issues. Many surveys have been shown that poor power quality causes large economic losses to industrial sectors and large amount of power is wasted due to power quality problems like sags, swells, harmonics, flickers etc. The present work considers, the modeling and simulation of a dynamic voltage restorer (DVR), which is achieved using MATLAB/Simulink. Faults are created with the proposed systems, and the disturbances are initiated at a duration of $0.8 \mathrm{sec}$ till $0.95 \mathrm{sec}$. Comparison of the performances of the Fuzzy neural and Fuzzy logic based DVR are presented. Results are showed that Fuzzy logic controller is able to restore the load voltage to the nominal value in both linear and non linear loads quickly and efficiently. But when the $2^{\text {nd }}$ and $3^{\text {rd }}$ harmonics are superimposed on the voltage sag and voltage swell by the application of 3-ph programmable source, the fuzzy logic controller fails to restore and reduce the harmonic content to an acceptable values which is according to IEEE standard 3\% for the individual voltage and 5\% for the three phase voltage. While the Fuzzy neural controller has been very powerful and efficient to restore the load voltage to the pre-sag value and make it smooth under different cases of faults and nonlinear load conditions and keep the harmonics within the permissible limits in all cases.
\end{abstract}

\section{Keywords}

Non-Linear Controller, Fuzzy Neural, Power Quality Improvement, Sags, Swells, DVR

\section{INTRODUCTION}

The electric power distribution system have huge networks with a large number of sources and loads are connected through a widespread distribution lines. Particularly the distribution systems have number of non-linear loads which affect the quality of power supplies. The smoothness of the waveform is lost due to non-linear loads, which cause many power quality problems. But the actual view of customers is to get the best quality of power and reliability of power supplies of the load centers in the area where they are located[1]. The reason for demanding high quality power during production process is mainly because of the modern manufacturing and process equipments that operate at high efficiency requires stable and trouble free power supply for the successful operation of their machines. Machines are sensitive to power supply variation are to be designed more precisely. For instance some instruments, like adjustable speed drives, automation devices, power electronic components etc fail into operation[2]. Actually the users of power systems should be supplied with a continuous flow of energy with defect free sinusoidal voltage at the promised magnitude level and freq, but in reality the criteria is total different, means that particularly the distribution systems, are having huge number of non-linear loads like induction motors, which have significant effect in the power system quality. The inability to provide the required quality of power output may sometimes cause complete shutdown of the industries which will make a significant financial loss to the industry concerned. However, balance due to degraded quality can not be simply put on to the hands of the utility itself. It has been observed that in industries, most of the conditions that can disrupt the process are generated within the factory itself. For example ,most of the non-linear loads are causing transient which can affect the reliability of the power supply. Also the power quality has serious economic implications for users, utilities and electrical equipment manufacturers, modernization and automation of industry involves increasing use of computers, microprocessors and power electronic systems, such as adjustable speed drives. The power electronic systems also contribute to power quality problems (generated harmonics). The electronic devices are very sensitive to disturbances and become less tolerant to power quality problems such as voltage sags, swells and harmonics. Due to occurring of harmonics in the system it will cause losses and heating of the motors[3]. So Dynamic voltage restorer (DVR)is one of the best suitable custom power devices for these types of power quality issues .It makes the load voltage at required magnitude and phase by compensating the voltage sag/swell and voltage unbalance at the point common coupling (PCC). DVR is able to compensate the voltage sags/swells by adding or subtracting appropriate voltages in series with the supply voltage and load point and thereby prevent unreliability power supply. Normally in steady-state operation DVR is not going to absorb /inject real power. But whenever voltage sag/swell or unbalance in supply voltage occurs in the system it will come into picture and supports the power system by injecting/absorbing real power instantly from d.c link. Here the d.c link can be energy storage elements like chargable battery or high capacity capacitor. This aim can be best achieved if the DVR is controlled by an appropriate modern control strategy. Generally the control strategy devised for a DVR should be able to offer a fast dynamic response, high robustness to parameter variations, sinusoidal load voltage with low total harmonic distortion and small steady-state errors . In addition it should be able to generate sinusoidal reference voltage for compensation voltage under distorted grid voltage condition. Many control strategies for single and three phase DVRs have been devised in the literature for achieving the aforementioned performance requirements. The feed-back control involves intensive computation to generate compensation voltage reference. Poor power quality may lead to failing or malfunctioning of the sensitive equipment, resulting in production and financial loss, also putting life at risk where safety is priority. In the industrial, service and transparent sectors the most common power quality problems are voltage sag and harmonics. Sag is a sudden decrease in the r.m.s voltage and make it between $10 \%$ and $90 \%$ from its nominal value, and lasting from 0.5 cycle to several seconds. Sag can be symmetrical or unsymmetrical, a three phase fault produce symmetrical sags. While single line to ground fault and double line to ground fault causes unsymmetrical sag. Harmonics is the presence of spectral components whose 
frequencies are multiplies the fundamental frequency. The harmonics occur due to non-linear load such as power electronics components and motors. According to the IEEE standards for the system of less than $69 \mathrm{kV}$ the harmonic distortion limits are $3 \%$ for individual voltage and $5 \%$ for total harmonic distortion. Harmonics cause overheating , overloading and additional losses to the transformers, motors and other power system equipment[4]. A Swell is a sudden increase in the r.m.s voltage and make it between $110 \%$ and $190 \%$ from nominal value, and lasting from 0.5 cycle to several seconds. The main reason for the swell is turn on the large capacitive loads and shutdown a large inductive loads. The Voltage interruption is decreased the voltage to less than $10 \%$ from its nominal value for a period not exceeding $1 \mathrm{~min}$. For improve the performance of the (DVR) Several studies have been conducted. These studies are shown that Artificial Intelligent controller for the DVR is effective and powerful in eliminating of power quality problems because that the DVR is non-linear in nature and needs a non-linear controller. In control unit Park transformation was used to reduce the three AC components $(\mathrm{Va}, \mathrm{Vb}, \mathrm{Vc})$ to two DC components $(\mathrm{Vd}$, Vq) to simplify the calculations, analysis and the control. Park transformation require the Phase Locked Loop to generate the reference signal in the same frequency and phase angle with the source signal . A Phase Advanced Compensation strategy for DVR was used where a closed loop controller that consists of an outer voltage loop and two inner current loop was proposed into the DVR control system. Inverter is the core of the DVR and a multilevel inverter was incorporated because of the high power and low harmonics in the output of this inverter. The capability of DVR to eliminate the power quality problems is demonstrated by MATLAB simulation.

\section{BASIC CONFIGURATION OF DVR}

DVR essentially as shown in fig. 1 consists of:

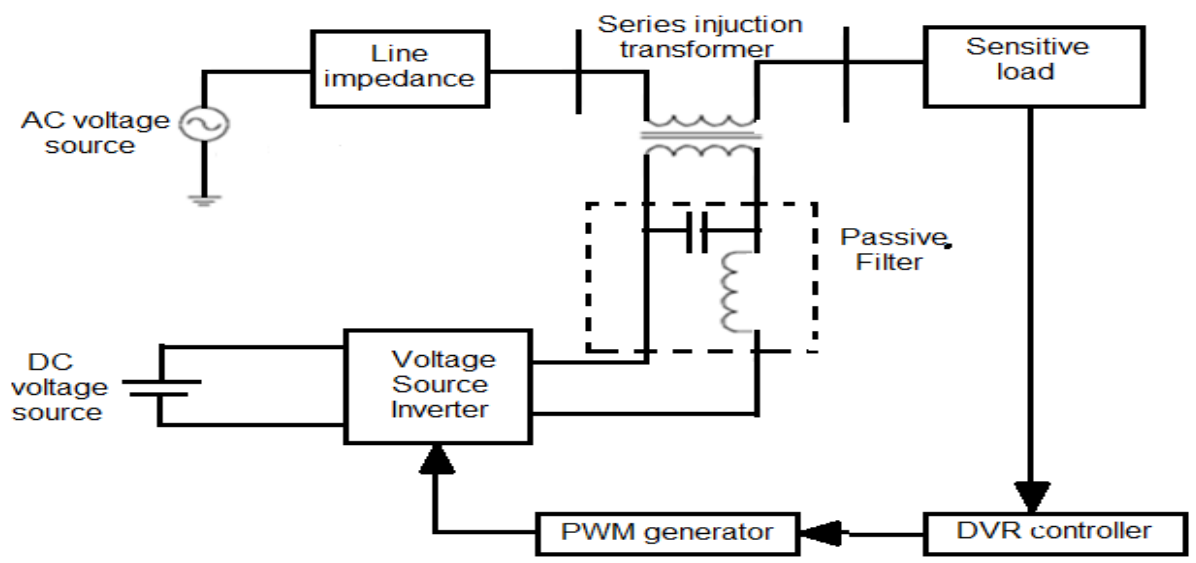

Fig. 1 The basic configuration of the DVR

\subsection{Power circuit}

i) Energy storage unit which can be Battery Energy Storage System[5], super capacitor[6], flywheel energy storage[7], wind energy[8], photo voltaic[9]. In this work Battery Energy storage System(BESS) was used because of the high stability for the (BESS).

ii) Inverter circuit

In this work the Three -Phase three-Level Inverter is used to converts the DC voltage from the (Battery Energy Storage
System) to a controllable three-phase AC voltage, which is equal to the compensating voltage. The structure of the threePhase three level inverter is shown in fig. 3 it consists of three arms,each arm is composed of four switches in series. Two diodes per arm to ensure the application of different voltage levels at the output of each arm. This structure allows generating an output voltage of three levels(E/2, $0,-\mathrm{E} / 2)$ as shown in table.1. and creates a neutral point $\mathrm{O}$ between the capacitors $\mathrm{C} 1$ and $\mathrm{C} 2$ therefore it is called NPC(neutral point clamped).
Table.1: The states of the three phase Three level inverter

\begin{tabular}{|c|c|}
\hline State of the switches & $\begin{array}{c}\text { Output voltage of } \\
\text { the Inverter }\end{array}$ \\
\hline $\mathrm{Q} 1, \mathrm{Q} 2$ on & $\mathrm{E} / 2$ \\
\hline $\mathrm{Q} 2, \mathrm{Q} 3$ on & 0 \\
\hline $\mathrm{Q} 3, \mathrm{Q} 4$ on & $-\mathrm{E} / 2$ \\
\hline
\end{tabular}

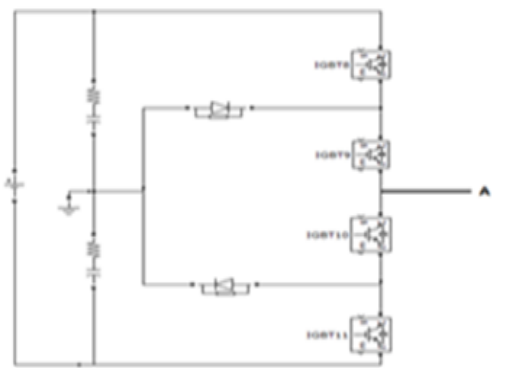

Fig. 3 Single phase three level inverter

\section{iii) Passive filter}

The filter unit eliminates the dominant harmonics and provide high quality of energy supply. The filter consists of inductors and capacitors. The filter can be placed either in high voltage side or in low voltage side of the injection transformer. The harmful effects of harmonics generated by 
the inverter can be reduced using the inverter side [10]. The inverter side filtering is proposed in this work to prevent The high- order harmonics currents from penetrating into the series transformer, thus reducing the voltage stress on the transformer.

iv) PWM (Pulse width Modulation)

There are several types of modulation technique used in DVR system such as hysteresis, PWM, deadbeat control and SVPWM (Space vector pulse width modulation)[12]. In this work sinusoidal PWM is used which involves the comparison of reference waveform(modulating signal) with a triangular wave (carrier wave) in order to get desired output voltage

v) Injection transformer

Three phase transformer or three single phase transformers are used to amplify the injected voltage from the inverter and creating an electrical isolation between the voltage source inverter (VSI) and the network also it ensures coupling between the PWM inverter and the network. The primary winding of the injection transformer is connected to the inverter side while its secondary winding is connected to the network and sensitive load .Over sizing the transformer is a common approach to avoide the inrush current.However,this would increase the size and weight of the DVR[11]

\section{OPERATING MODES OF DVR}

i)- Protection mode

The DVR isolated from the system when the fault occurs on the load side or inrush a large current, a protection device is used namely( by-pass switch) as shown in the Figure.4 $\mathrm{S} 1, \mathrm{~S} 2, \mathrm{~S} 3$ is a by- pass switch. S1 and S2 will be open and S3 provide alternating path for the fault current

ii) Standby mode

When the error in the load voltage is zero the DVR will not inject any voltage to the system as shown in the fig.5 The converter in the inverter side prevents any current from passes to the injected transformer.

iii) Injection mode

The DVR injects the compensating voltage (the difference between the sag and pre-sag voltage) through the injecting transformer as shown in fig.6

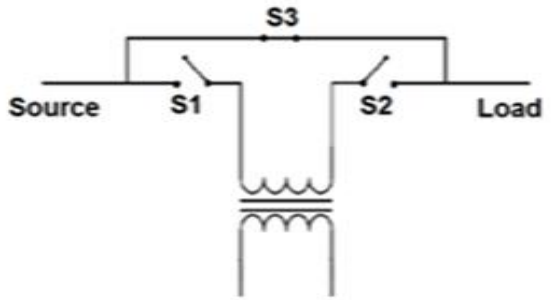

Fig 4 Protection mode of the DVR
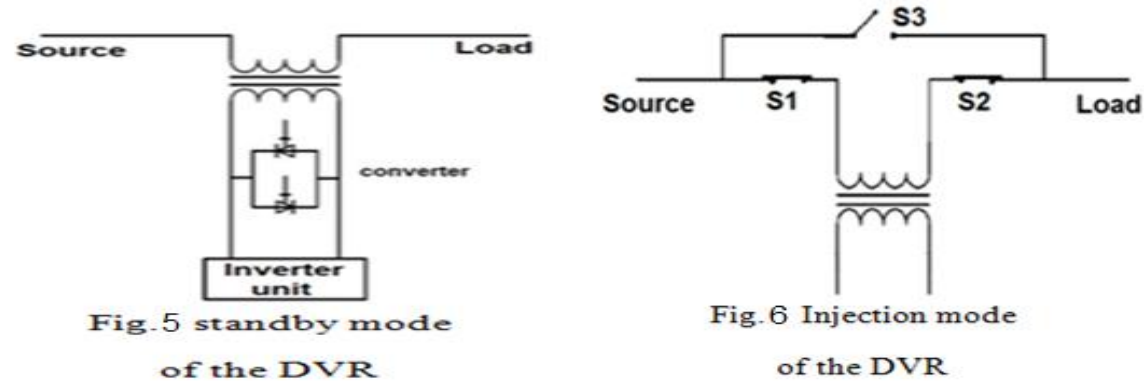

Fig. 6 Injection mode

of the DVR

\section{THE LOCATION OF THE DVR}

i)At the medium voltage as shown in fig.7 the DVR is connected to $11 \mathrm{kVr}$.m.s radial distribution feeder that supplies the load's transformer

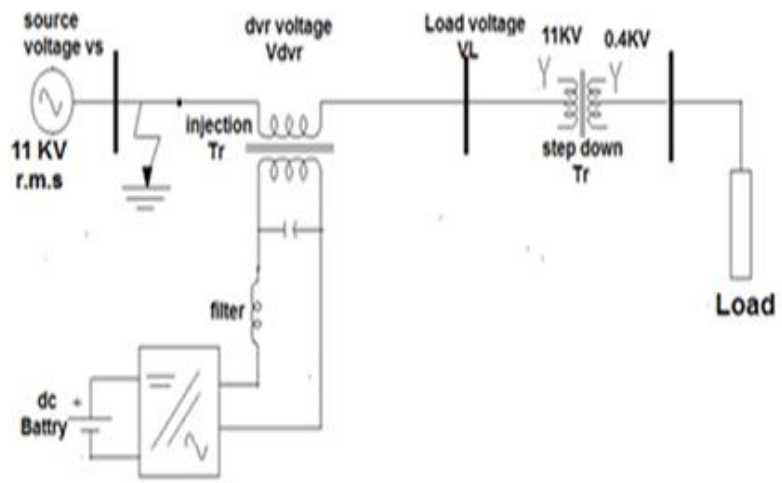

Fig. 7 The DVR connected to the medium voltage

\section{PARK TRANSFORMATION}

Park transformation is transform the three AC quantities to two DC quantities to simplify calculations and analysis[13].
ii)At low voltage as shown in the fig. 8 the DVR is connected to the secondary winding of the load's transformer which is $400 \mathrm{~V}$

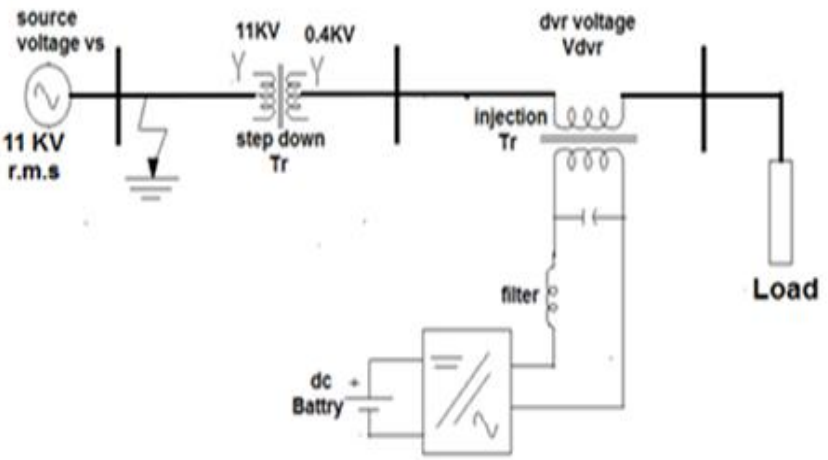

Fig.8 The DVR connected to the low voltage 


$$
\left[\begin{array}{l}
d \\
q \\
0
\end{array}\right]=\sqrt{\frac{2}{3}}\left[\begin{array}{ccc}
\cos (\theta) & \cos \left(\theta-\frac{2 \pi}{3}\right) & \cos \left(\theta+\frac{2 \pi}{3}\right) \\
-\sin (\theta) & -\sin \left(\theta-\frac{2 \pi}{3}\right) & -\sin \left(\theta+\frac{2 \pi}{3}\right) \\
\sqrt{\frac{1}{2}} & \sqrt{\frac{1}{2}} & \sqrt{\frac{1}{2}}
\end{array}\right]\left[\begin{array}{l}
a \\
b \\
c
\end{array}\right] .
$$

Park transformation require the Phase Locked Loop to generate the reference signal with the same frequency and the phase angle of the actual signal

\section{DYNAMIC VOLTAGE RESTORER BASED ON FUZZY LOGIC CONTROLLER}

In recent years there has been a very significant increase in the number of applications of Fuzzy logic controller . Currently, there are numerous products on the market which use fuzzy logic control(mostly designed in Japan). Yasunobu and Miyamoto at Hitachi have designed a fuzzy controller for the Automatic train control (ATO) system which has been in use in the city of Sendai, Japan since July 1987. The two main operations of the system are Constant Speed Control(CSC) and Train Automatic Stop Control(TASC)[14]. Another application using Fuzzy logic controller is the Radio control of oral instructions on an unmanned helicopter used to sea rescue[15]. These applications have already produced results which illustrate the strength of the fuzzy logic control technology

\section{THE STRUCTURE OF THE FLC CONSIST OF FIVE COMPONENTS}

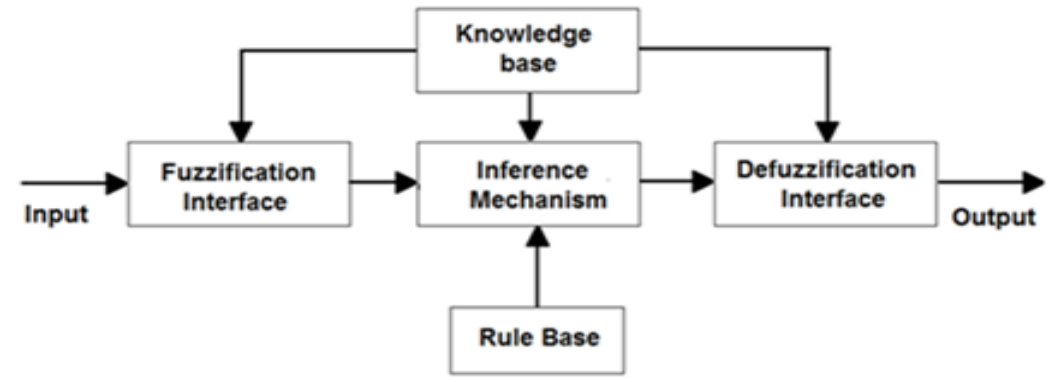

Fig.9 The basic configuration of fuzzy logic controller

\section{i) Fuzzification Interface}

It is the process that convert a crisp input signals, error and change of error into fuzzified signals in the fuzzy sets.

\section{ii) Knowledge base}

Is the data base which is consist of input and output membership functions as shown in the figures below.

\section{iii) Rule base}

It consists of a set of linguistic rules as shown in the table. 2

\section{iv) Inference mechanism}

It infers the fuzzy control action from the knowledge base and rule base to convert the input conditions to fuzzified output.

v) Defuzzification interface

It is the process of converting the controller output in linguistic labels represented by fuzzy set to crisp control signals. In this work centroid method is used for defuzzification. 


\section{Input and output membership function for fuzzy logic controllers}

First controller

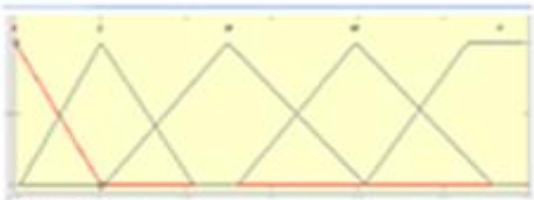

Fig. 10 Input membership function for first controller voltage error

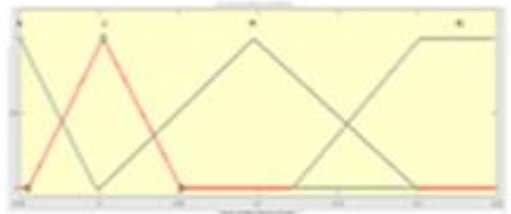

Fig.11 Input membership function for first controller change of enror

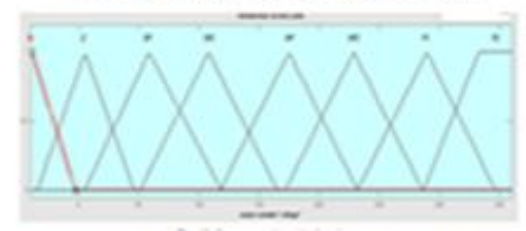

Fig.12 Output membership function for first controller second controller

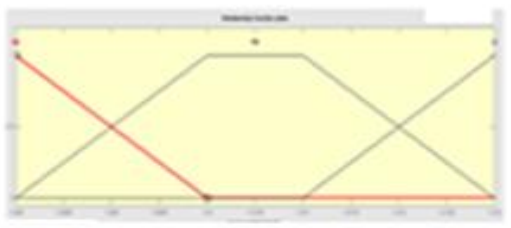

Fig.13 Input membership function for second controller voltage enror

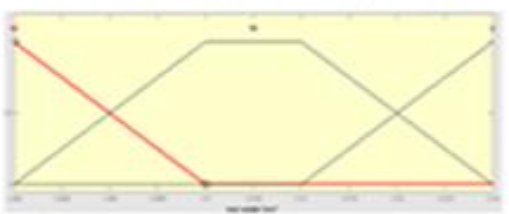

Fig.14 Input membership function for second controller change of error

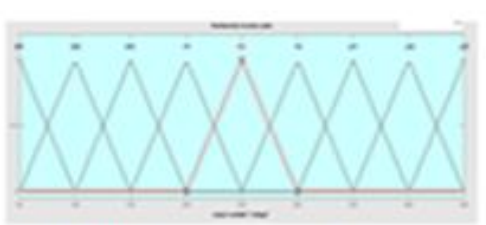

Fig.15 Output membership function for second controller
Third controller

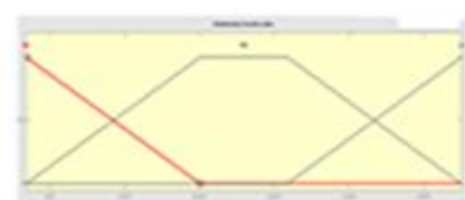

Fig.16 Input membership function for third controller voltage error

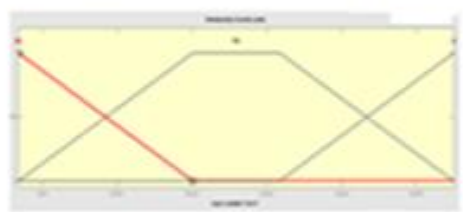

Fig.17 Input membership function for third controller

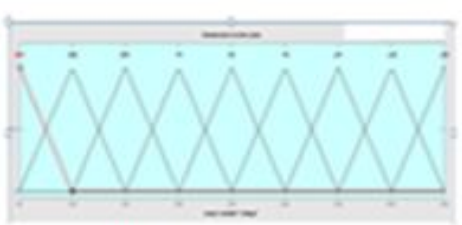

Fig.18 Output membership function for third controller
The rules set for Fuzzy logic controllers

Table.3: The rules set for the second controller

\begin{tabular}{c|c|c|c|}
$\mathrm{e}^{\Delta \mathrm{e}}$ & $\mathrm{SP}$ & $\mathrm{MP}$ & $\mathrm{P}$ \\
\hline $\mathrm{SP}$ & SP1 & SP2 & SP3 \\
\hline MP & MP1 & MP2 & MP3 \\
\hline $\mathrm{P}$ & LP1 & LP2 & LP3 \\
\hline
\end{tabular}

Table.4: The rules set for the Third controller

\begin{tabular}{c|c|c|c|}
$\mathrm{e}^{\Delta \mathrm{e}}$ & $\mathrm{SP}$ & $\mathrm{MP}$ & $\mathrm{P}$ \\
\hline SP & SP1 & SP2 & SP3 \\
\hline MP & MP1 & MP2 & MP3 \\
\hline $\mathrm{P}$ & LP1 & LP2 & LP3 \\
\hline
\end{tabular}

Table.5: The set of linguistic rules

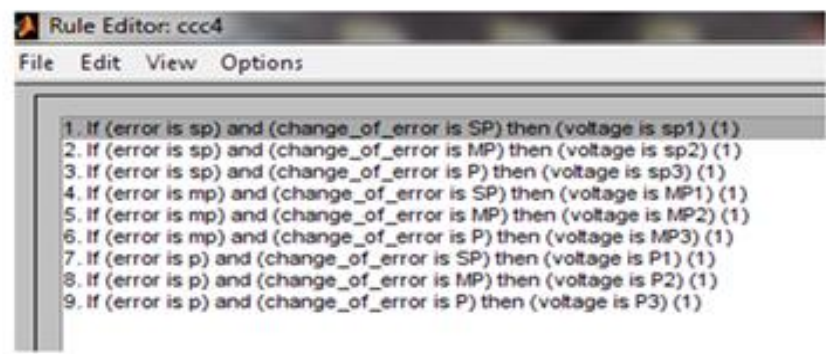




\section{DYNAMIC VOLTAGE RESTORER BASED ON FUZZY NEURAL CONTROLLER}

\section{i) Artificial Neural Networks(ANN)}

Artificial Neural Network is an information processing system whose characteristics are similar to a biological neural systems. It was designed based on the human brain. ANN has been widely used because of its accuracy and its ability to develop complex nonlinear models

\section{ii) Artificial Neuron}

Neurons in human brain act as atool that can perform processing of information of human senses. McCulloch and
Pitt(1943) proposed a model neuron that has the characteristics of the transmission and receipt of information process that is similar to the process that occurs in biological neurons. This neuron was becoming a reference in the development of ANN. A neuron plays a role in determining the function and operation of the network. The mathematical models of neurons shown in the Fig.19 Can be represented by the following equation:[16].

$\mathrm{O} / \mathrm{P}=\mathrm{F}[\mathrm{x} 1 * \mathrm{~W} 1+\mathrm{X} 2 * \mathrm{~W} 2+\mathrm{X} 3 * \mathrm{~W} 3+\mathrm{X} 4 * \mathrm{~W} 4+$ bias $]$

The output of the neuron is dependent on the activation function

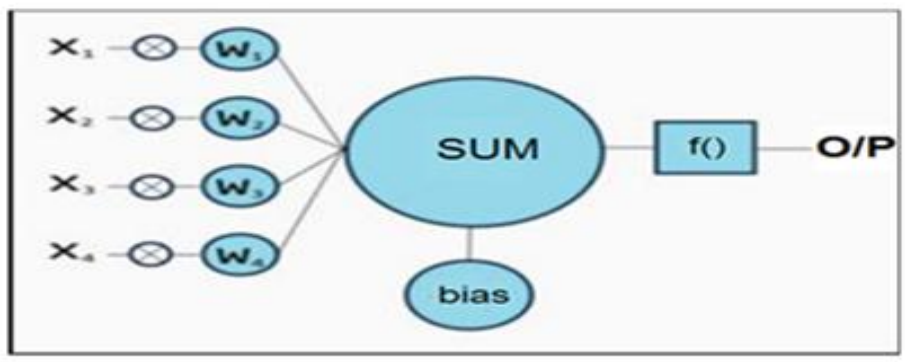

Fig.19 Artificial Neuron

\section{iii) Activation Function}

There are several types of a non-linear, Differentiable activation functions, a non-linear activation functions can be used in networks trained with back propagation method. Hyperbolic tangent function[17] Tanh $(x)=\frac{\exp (x)-\exp (-x)}{\exp (x)+\exp (-x)}$

The output range of the tanh function is between -1 and 1 . Logistic function [17]. $\quad f(x)=\frac{1}{1+\exp (-\beta x)}$

$\beta$ is the slope constant, and it always consider to be one but it can be changed. The output range of the logistic function is between 0 and 1 .

\section{iv) Single Layer Neural Network}

The most simple form of the Neural Network in which only one layer of input nodes that send weighted input to subsequent

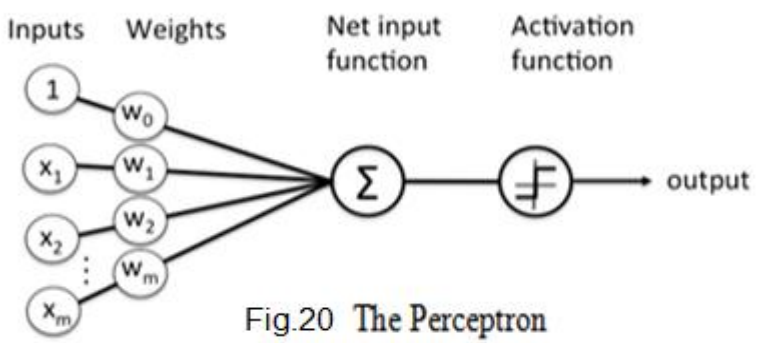

vii) Adaptive Neuro Fuzzy Inference System(ANFIS) Is a combination of two methods Artificial neural network (ANN) and Fuzzy logic(FL). The ANN can be used to adjust the MFs and determined the set of rules in Fuzzy logic [18]. layer of receiving nodes. Neurons are grouped into layers and layers are grouped into networks to form highly interconnected processing structures. One of the early examples of a singlelayer neural network was called a "perceptron

\section{v) Rosenblatt's Perceptron}

Is a neural network composed of a single layer feed-forward network using threshold activation function as shown in fig.20

Threshold function is a non-differentiable, non-linear and its output either 0 or 1

\section{vi) Multilayer Neural Network (MLN)}

Neural Network which contains one or more hidden layers is called Multilayer Neural Network or Multilayer

Perceptrons(MLP) as shown in fig.21. Each hidden layer uses the same activation function

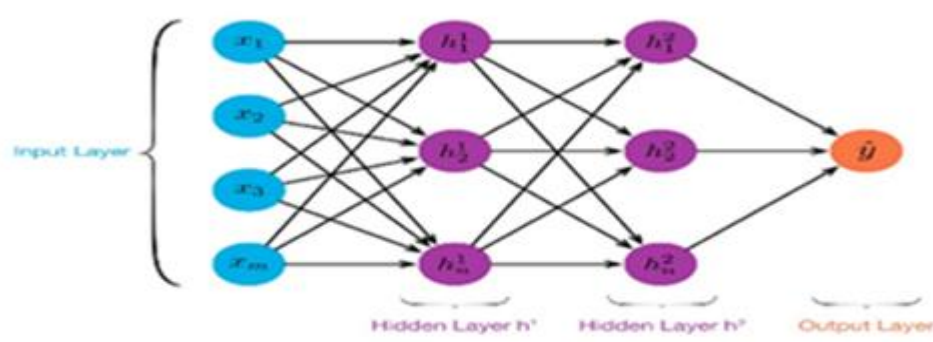

Fig.21 Multilayer Neural Network

\section{viii) ANFIS Architecture}

Is an adaptive network that uses supervised learning algorithm the function of ANFIS is similar to the Takagi-Sugeno fuzzy inference system 


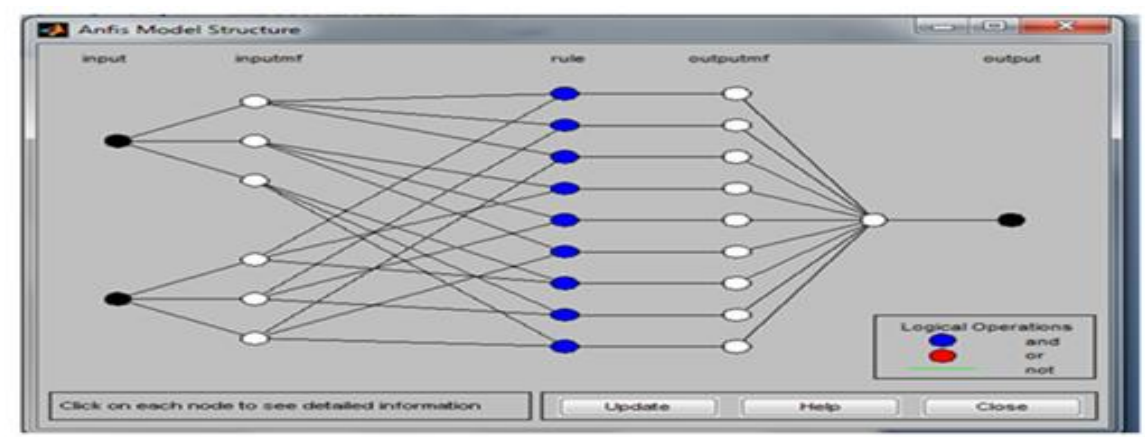

Fig.22 ANFIS Structure

It is clear from fig.22, ANFIS architecture has five layers [19].These layers is as follows:

Layer 1: It contains an adaptive nodes to a function parameter. The output from each node is a degree of membership value that is given by the input of the membership function

Layer 2: all nodes in this layer is fixed or nonadaptive. The output from each node is the result of multiplying of signal coming into the node and delivered to the next node. Each node in this layer represents the firing strength for each rule

Layer 3: The nodes in this layer is fixed or nonadaptive. Each node is a calculation of the ratio between the individual rule

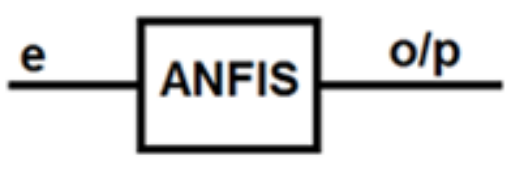

Fig.23 ANFIS optimize PI firing strength and the sum of all rules' firing strength. This result is known as the normalized firing strength.

Layer 4: The nodes in this layer is an adaptive node to an output

Layer 5: The node in this layer is a fixed or nonadaptive node This node is computed the output from the summation of all incoming signals from the previous node

\section{ix) Types of ANFIS}

There are two types of ANFIS optimized PI controller whose contain one input(error) and one output as shown in fig. 23 and ANFIS optimized Fuzzy logic controller whose contain two input(error and change of error)and one output as in Fig.24

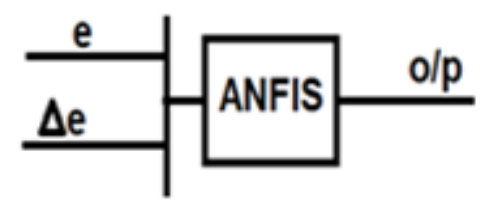

Fig.24 ANFIS optimize fuzzy logic

better results than fuzzy logic when we added the $2^{\text {nd }}$ and $3^{\text {rd }}$ harmonics to the sag and swell

\section{x) Flow chart for ANFIS algorithm}

The flow chart for ANFIS algorithm is as shown in Fig.25 


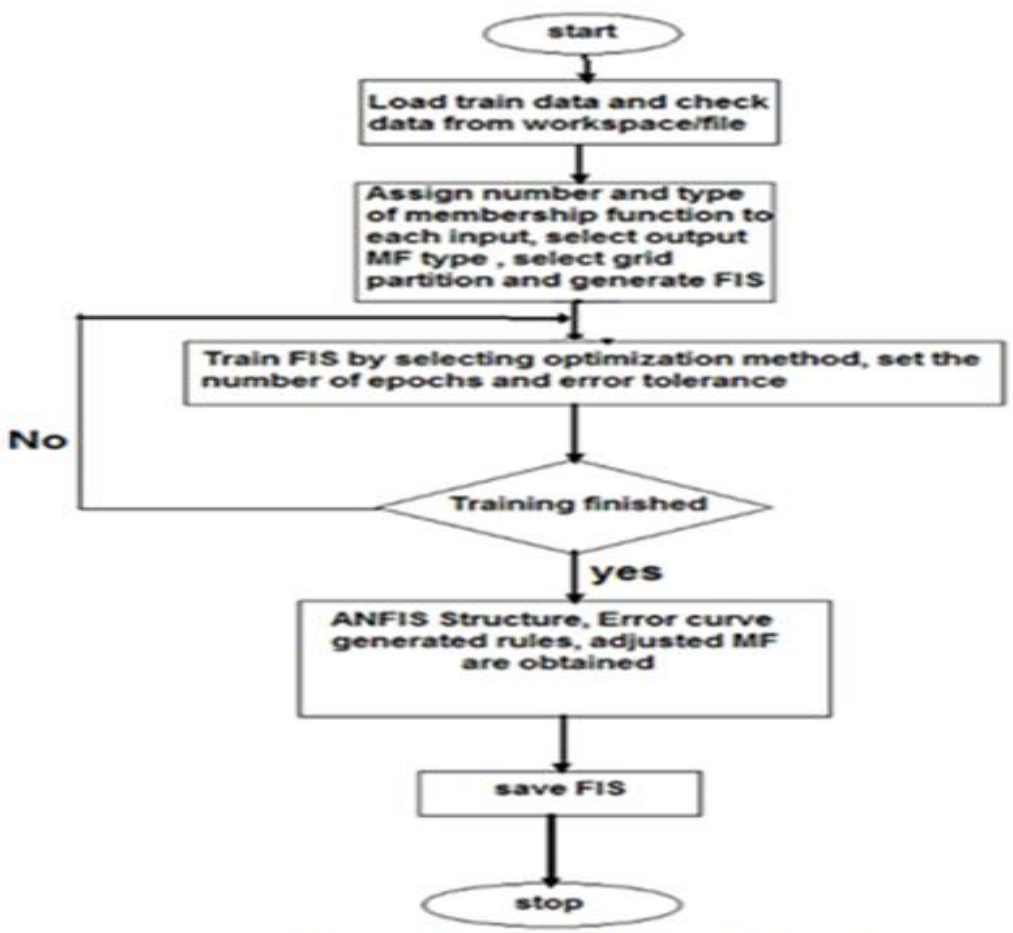

Fig.25 flow chart for ANFIS algorithm

\section{xi) Train data and ANFIS editor for the fuzzy neural controllers.}

The train data of ANFIS is shown in tables $(6,7,8)$. And the editors of ANFIS are shown in figures $(26,27,28)$.
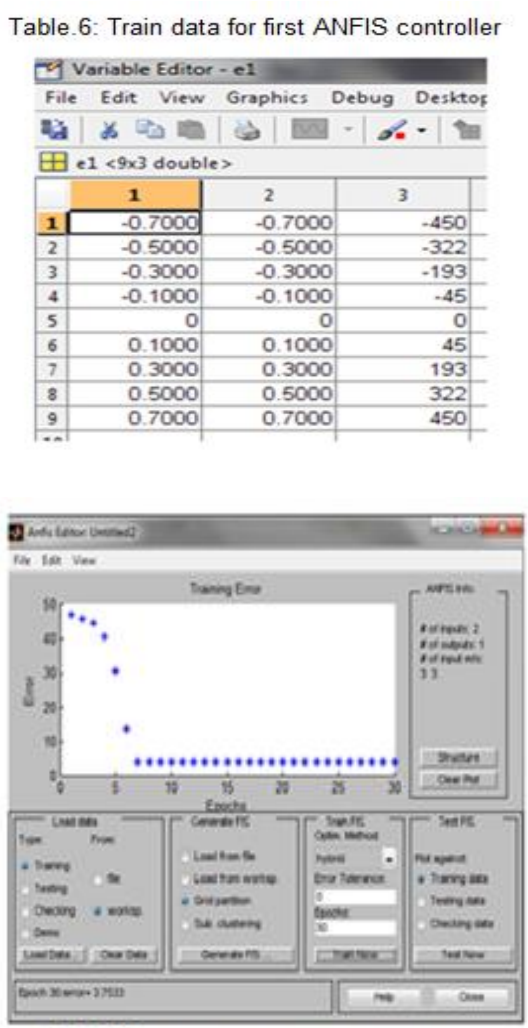

Fig.26 ANFIS editor for first controller
Table.7: Train data for second ANFIS controller
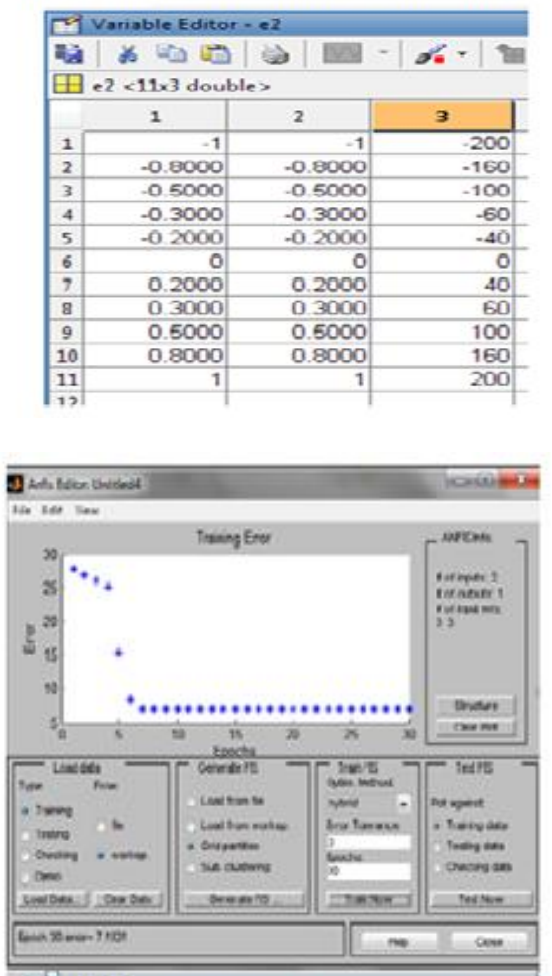

Fig.27 ANFIS editor for second controller
Table.8: Train data for third ANFIS controller
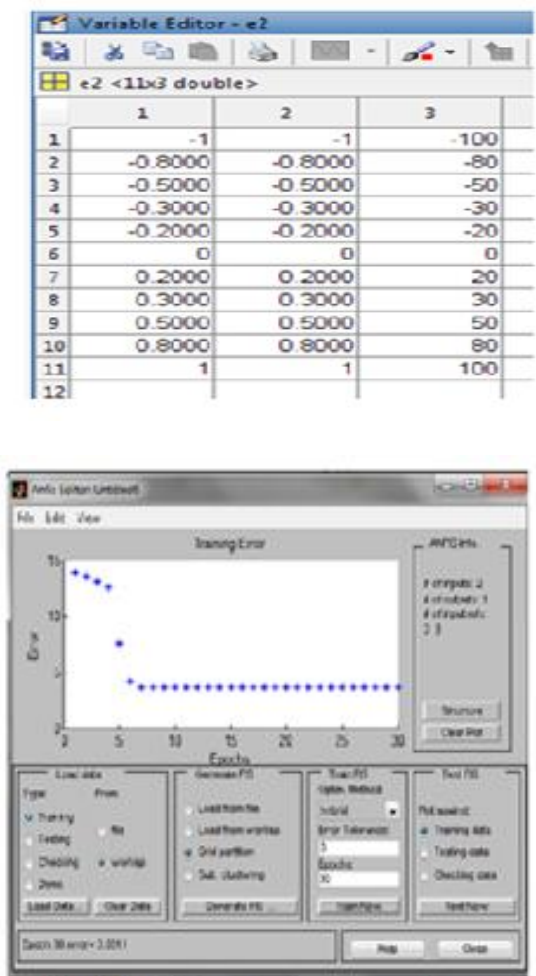

Fig.28 ANFIS editor for third controller 


\section{THE SIMULATION AND RESULTS}

The performance and efficiency of the DVR based on Fuzzy logic and Fuzzy neural will be tested with linear loads and non-linear loads.

\section{i) Linear load}

The simulation and modeling of the system with DVR are shown in Fig.29 The control unit for the DVR based on Fuzzy neural controller is shown in figures. 30

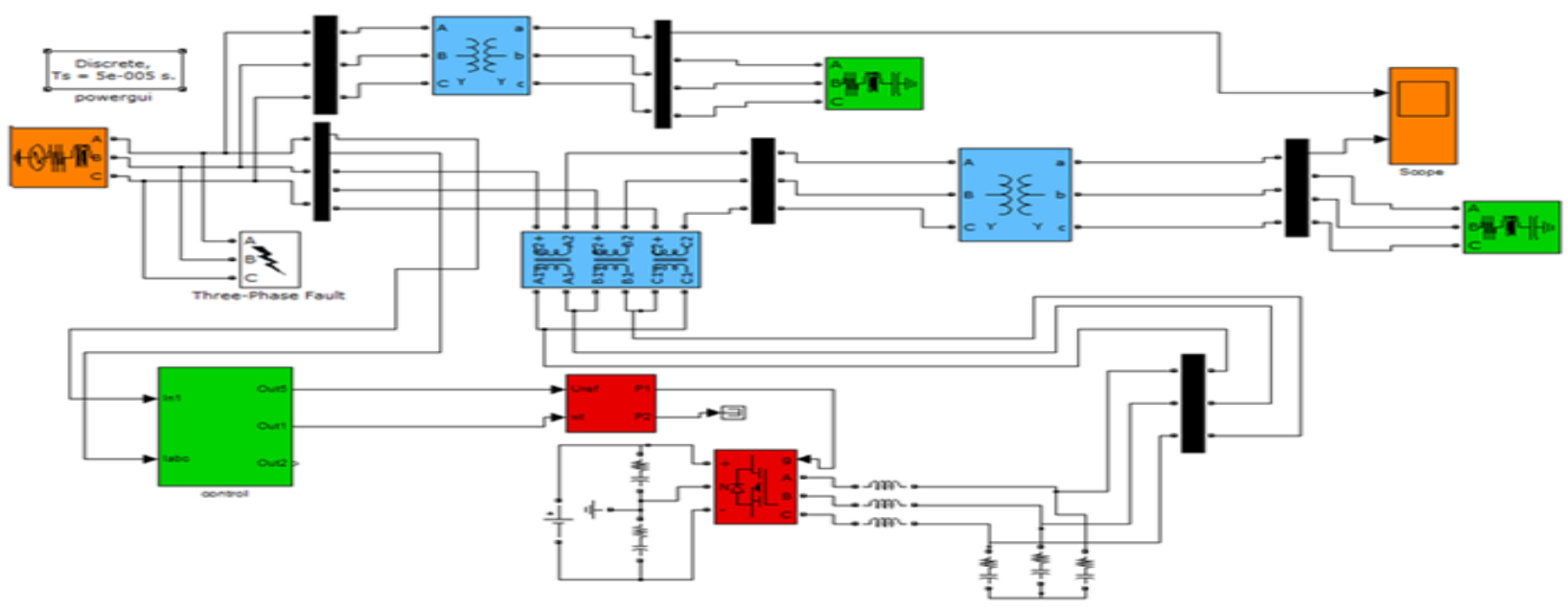

Fig.29 The simulink model of the test system with linear load

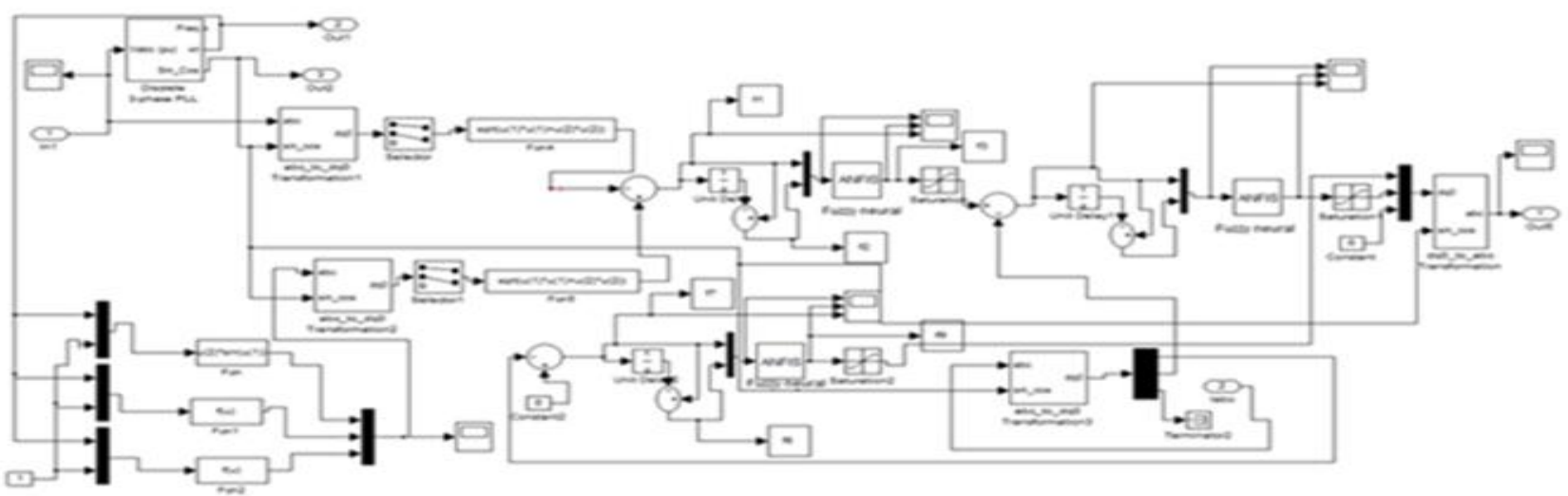

Fig.30 Control unit for the DVR based on Fuzzy Neural Controller

\section{i) Linear loads}

It is clear from the figures below that the Fuzzy logic controller and Fuzzy neural controller are capable of track and restore the load voltage fastly to its nominal value and keep the (THD) within acceptable limits. But when we added $2^{\text {nd }}$ and $3^{\text {rd }}$ harmonics to the voltage as shown in figures.37,38 only Fuzzy neural was capable to keep the harmonics within permissible limits while Fuzzy logic was able to restore waveform only but was unable to keep the (THD) within acceptable limits.

1-Single line to ground fault: In figures 31. SLGF(unsymmetrical sag) is simulated. It is started from $0.8 \mathrm{~s}$ and it is kept until $0.95 \mathrm{~s}$. The load voltage is kept at the nominal value with the help of the DVR based on Fuzzy logic and Fuzzy neural.

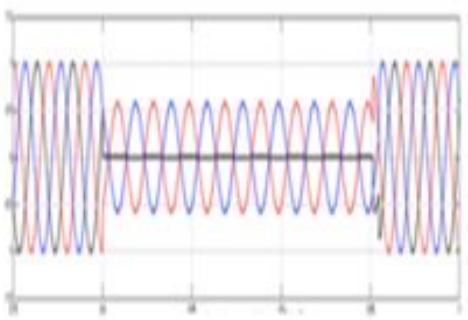

(a)

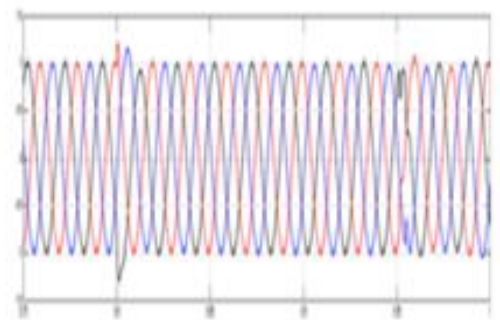

(b)

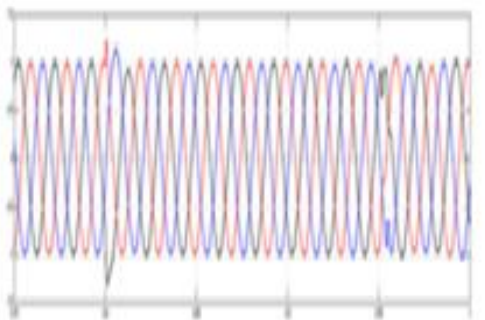

(c)

Fig.31 (a) Load voltage without DVR (b) Load voltage with DVR based on Fuzzy logic controller (c) Load voltage with DVR based on Fuzzy neural controller 
2-Double line to ground fault

As shown in figures 32 . DLGF(unsymmetrical sag) is simulated. It is started from $0.8 \mathrm{~s}$ and it is kept until $0.95 \mathrm{~s}$. DVR

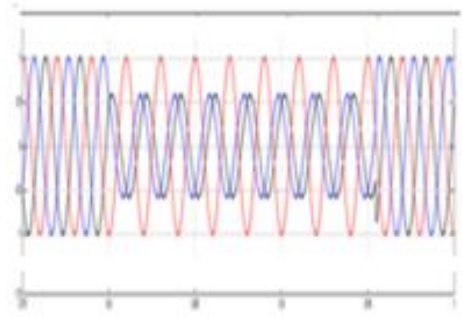

(a)

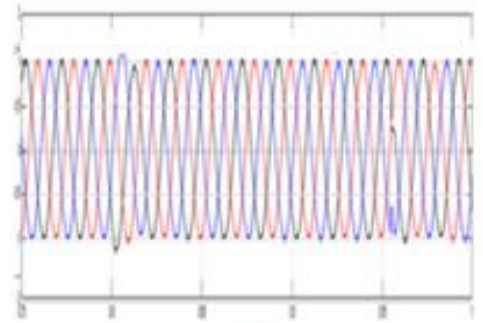

(b) based on Fuzzy logic and Fuzzy neural is restored the load voltage to the nominal value

Fig.32 (a)Load voltage without DVR (b) Load voltage with DVR based on Fuzzy logic controller (c) Load voltage based on Fuzzy neural controller

3-Three phase fault: In figures 33. Three phase to ground fault(symmetrical sag) is simulated. It is started from $0.8 \mathrm{~s}$ and it is kept until $0.95 \mathrm{~s}$. The load voltage is kept at the nominal

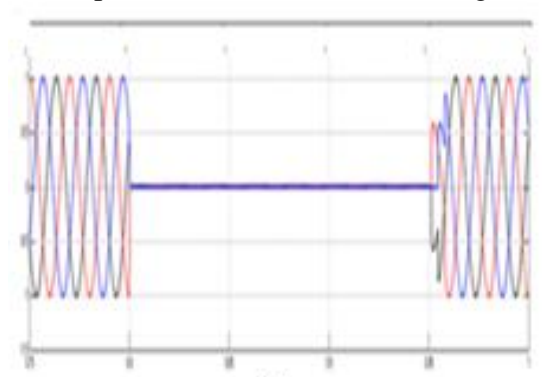

(a)

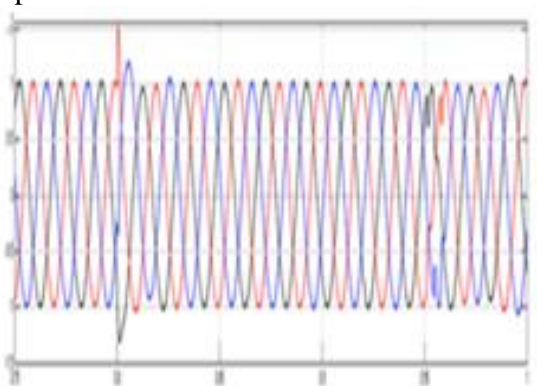

(b)

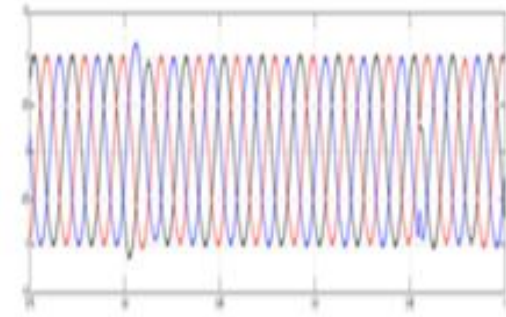

(c)

value with the help of the DVR based on Fuzzy logic and Fuzzy neural

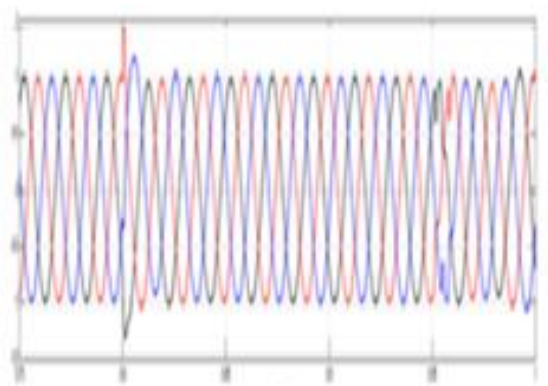

(C)

Fig.33 (a)Load voltage without DVR (b) Load voltage with DVR based on Fuzzy logic controller (c) Load voltage based on Fuzzy neural controller

4-Sag: In figures 34. Symmetrical sag is simulated. It is started from $0.8 \mathrm{~s}$ and it is kept until $0.95 \mathrm{~s}$. Figures.34(b) and (c) show the load voltage with compensation. As a result of the DVR based on Fuzzy logic and Fuzzy neural, the load voltage is kept at pre-sag voltage.

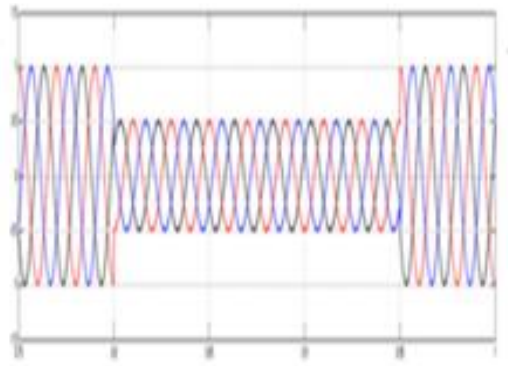

(a)

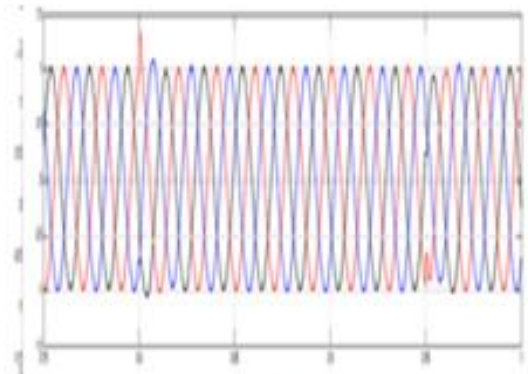

(b)

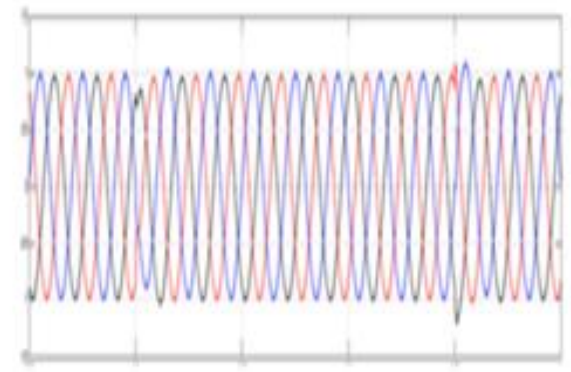

(c)

Fig.34 (a)Load voltage without DVR (b) Load voltage with DVR based on Fuzzy logic controller (c) Load voltage based on Fuzzy neural controller

5-Swell: As shown in figures.35 the three phase will be swelled to $150 \%$ for $0.15 \mathrm{~s}$ from $0.8 \mathrm{~s}$ to $0.95 \mathrm{~s}$. As can be seen the load voltage is kept at the nominal value with the help of the DVR based on Fuzzy logic controller and Fuzzy neural controller.

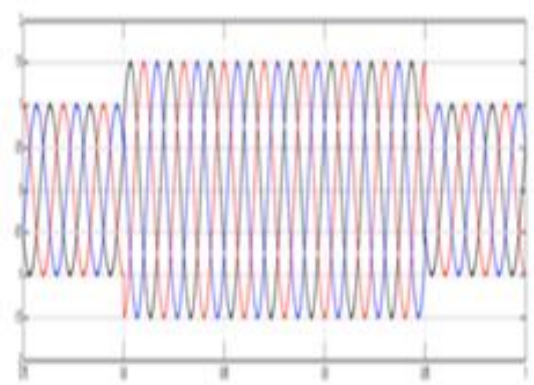

(a)

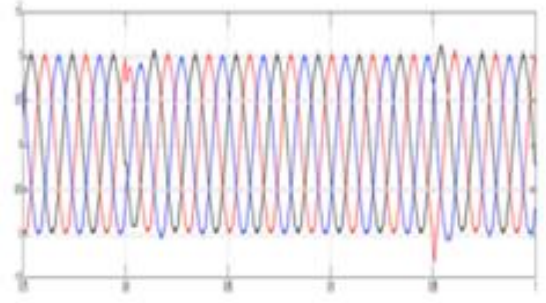

(b)

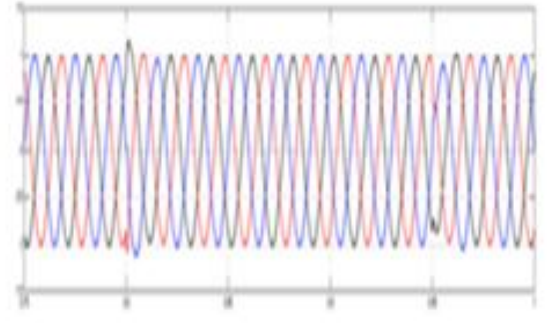

(c)

Fig. 35 (a)Load voltage without DVR (b) Load voltage with DVR based on Fuzzy logic controller (c) Load voltage based on Fuzzy neural controller 
6-Sag with $2^{\text {nd }}$ order harmonic and $3^{\text {rd }}$ order harmonic As shown in figures.36 three phase sag with presence $2^{\text {nd }}$ and $3^{\text {rd }}$ harmonics is simulated. It is initiated from $0.8 \mathrm{~s}$ to $0.95 \mathrm{~s}$. As can be seen, the load voltage kept at pre-sag voltage and without harmonic distortion with the help of the DVR based on Fuzzy neural. DVR based on Fuzzy logic was incapable to restore the load voltage to the pre-sag value and kept the THD within acceptable limits

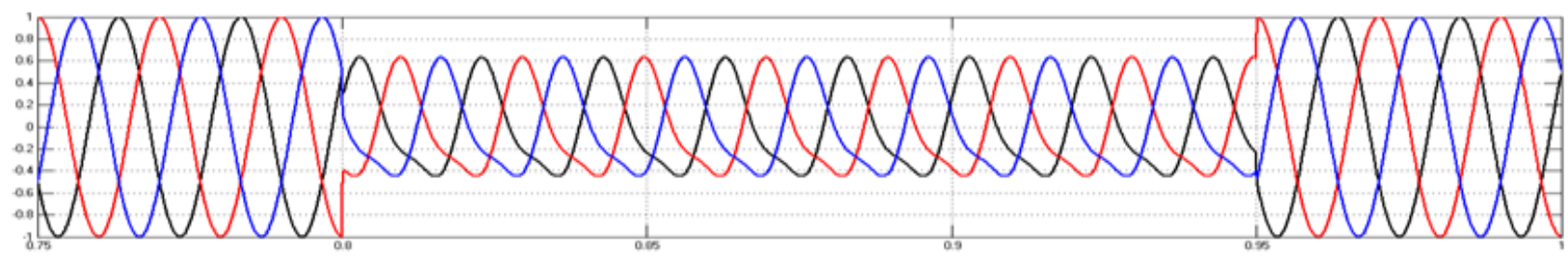

(a)

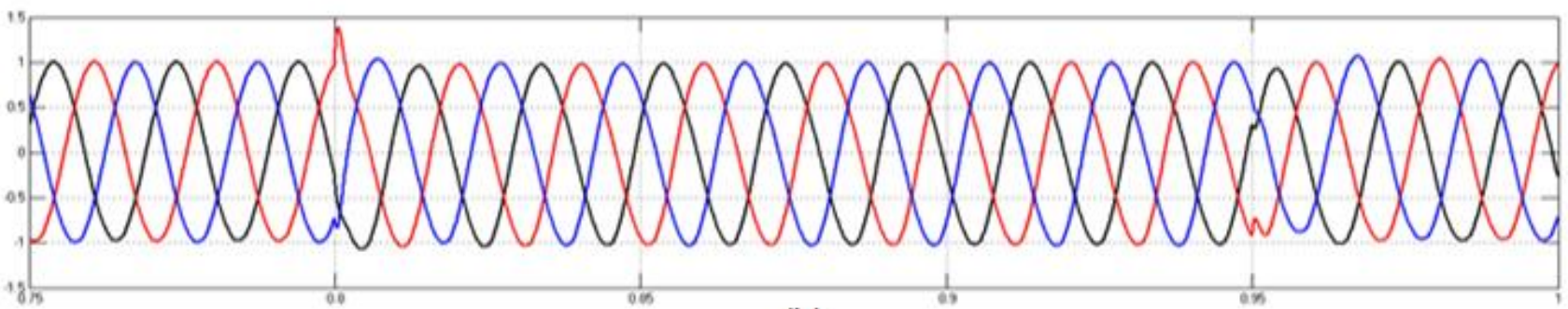

(b)

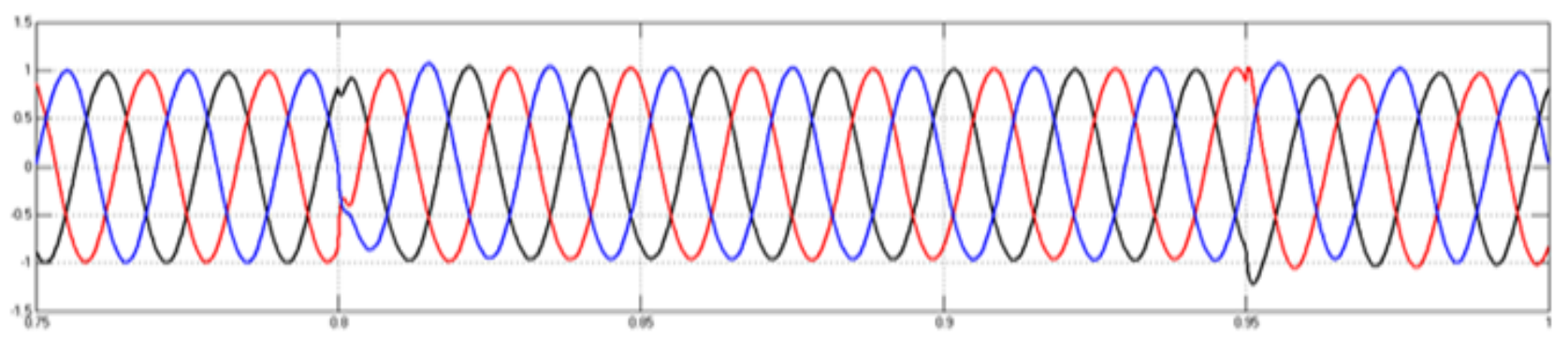

(c)

Fig.36 (a) load voltage without DVR (b) Load voltage with DVR based on Fuzzy logic controller (c) Load voltage with DVR based on Fuzzy neural controller

7-Swell with $2^{\text {nd }}$ order harmonic and $3^{\text {rd }}$ order harmonic As shown in figures. 37 three phase swell with presence $2^{\text {nd }}$ and $3^{\text {rd }}$ harmonics is simulated. It is initiated from $0.8 \mathrm{~s}$ to $0.95 \mathrm{~s}$. From the results, the load voltage kept at nominal value and within permissible total harmonic distortion with DVR based on Fuzzy neural. While DVR based on Fuzzy logic was incapable to restore the load voltage to the pre-swell value and kept the THD within acceptable limits

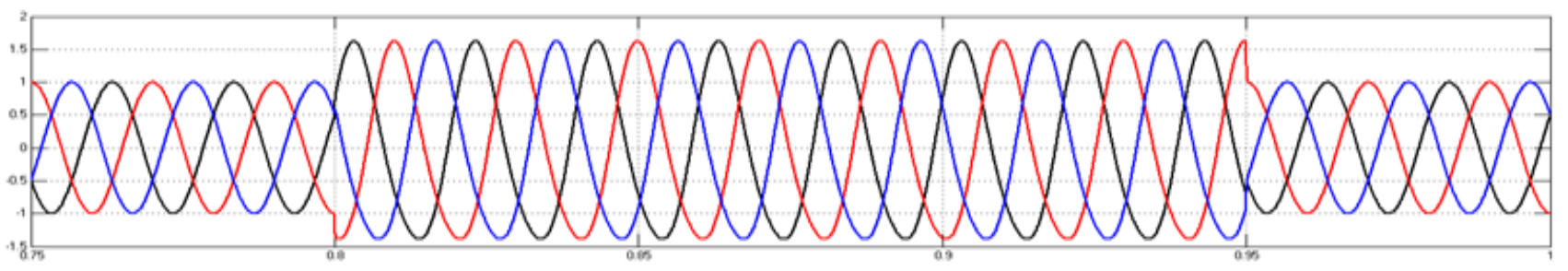

(a) 


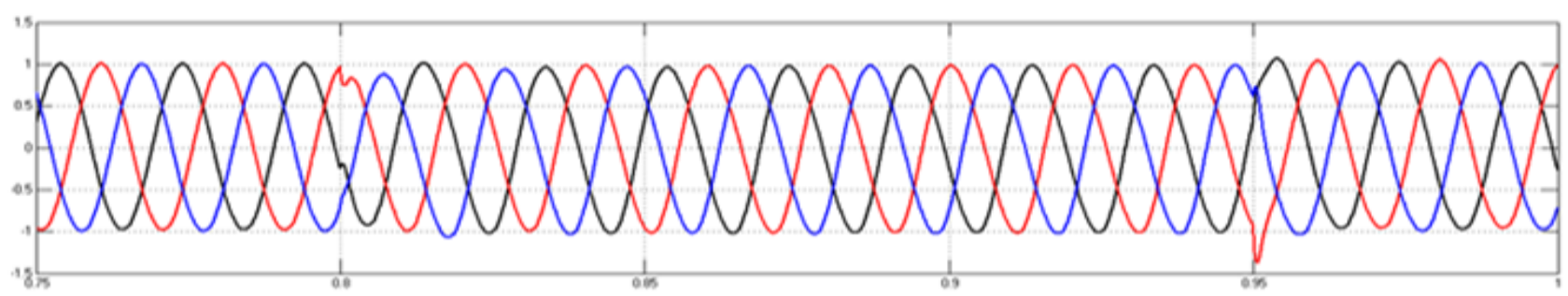

(b)

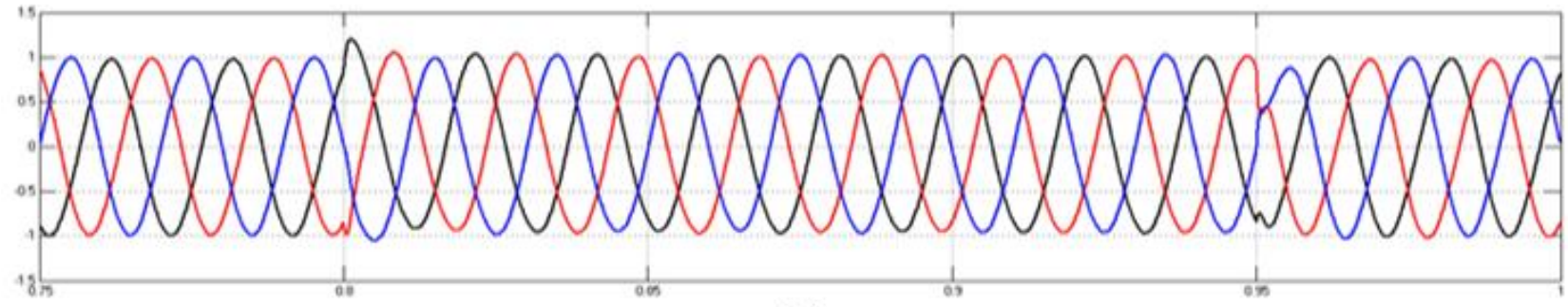

(c)

Fig.37 (a) Load voltage without DVR (b) Load voltage with DVR based on Fuzzy logic controller (c) Load voltage with DVR based on Fuzzy neural controller

ii) Non linear load

The Simulink model with non-linear load is also investigated.

The system and DVR are shown in Fig.38. The non-linear load is 3-ph rectifier which supplies d.c machine. It is clear from the figures. 39, 40 that the Fuzzy logic controller and Fuzzy neural controller are able to restore the load voltage vastly to its nominal value and keep the (THD) within acceptable limits.

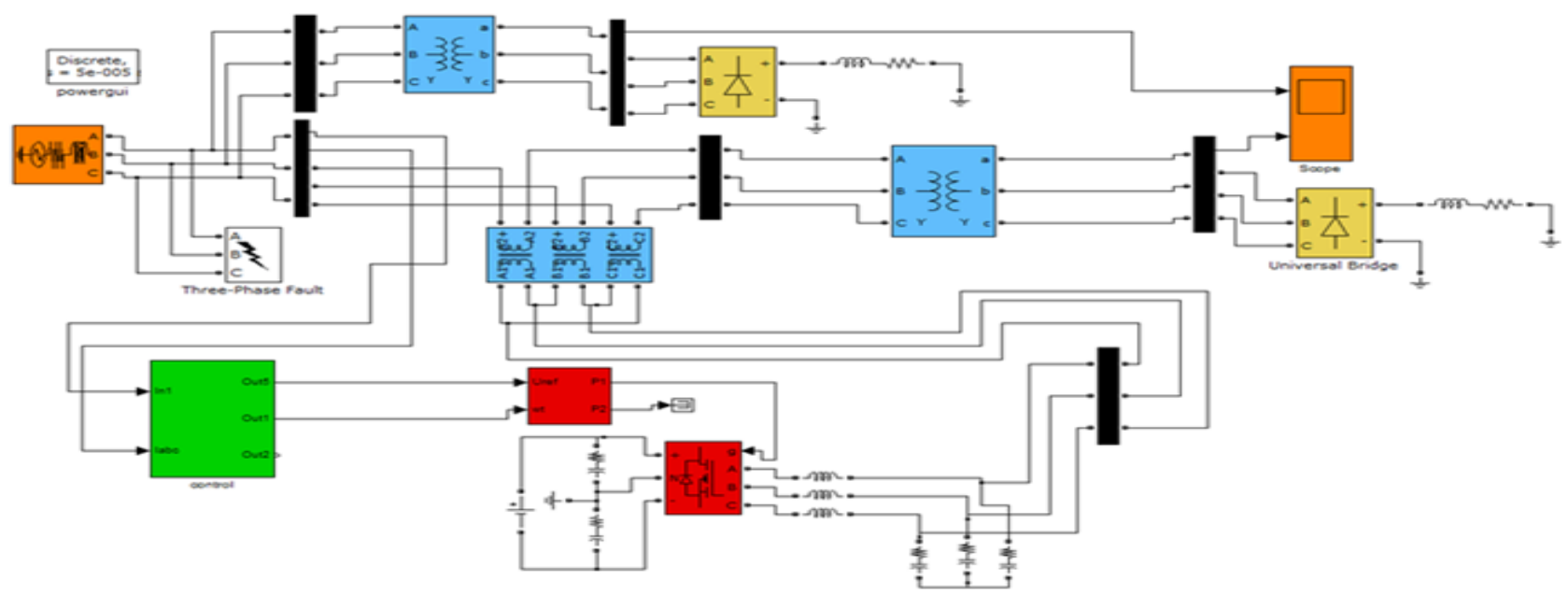

Fig. 38 The simulink model of the test system with nonlinear load

1-Sag

Three phase sag is simulated as shown in figures.39. The load voltage with compensation is shown in figures.39.(b),(c).
DVR based on Fuzzy logic and based on fuzzy neural was capable to restore the load voltage to its pre-sag value.

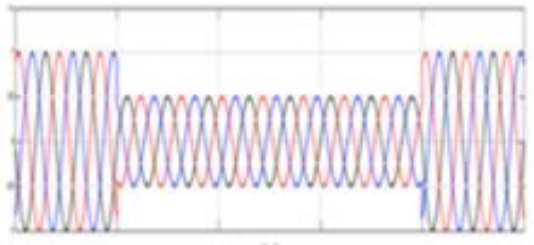

(a)

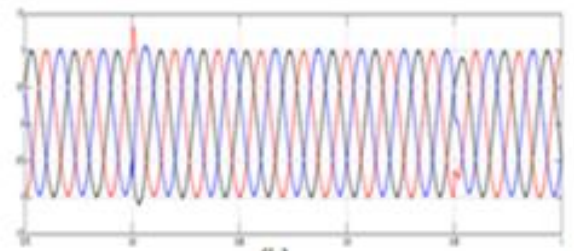

(b)

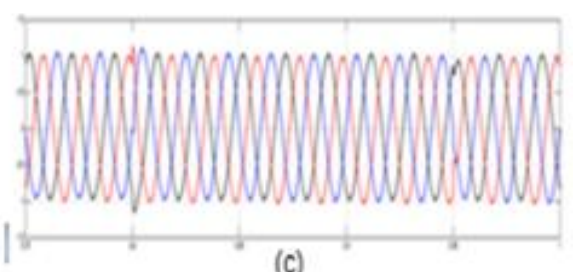

(c)

Fig.39 (a) Load votage without DVR (b) Load votage with DVR based on Fuzzy logic controller (c) Load votage based on Fuzzy neural controller 
2-Swell

Three phase swell is simulated as shown in figures.40. The load voltage with compensation is shown in figures.39.(b),(c).
DVR based on Fuzzy logic and based on fuzzy neural was able to keep the load voltage to its pre-swell value

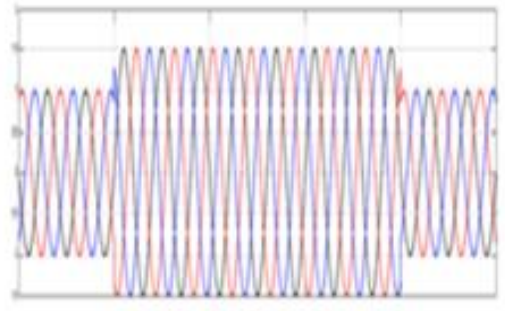

(a)

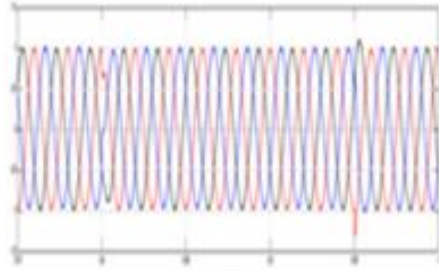

(b)

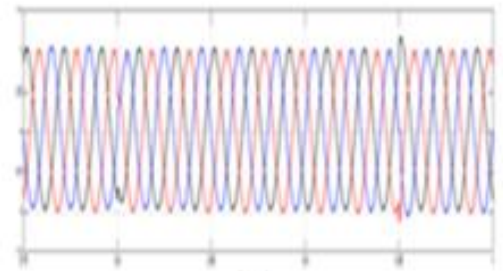

(c)

Fig.40 (a) Load voltage without DVR (b) Load voltage with DVR based on Fuzzy logic controller (c) Load voltage based on Fuzzy neural controller

\section{COMPARISON OF TOTAL HARMONIC DISTORTION(THD) LEVELS FOR DIFFERENT TYPES OF LOADS}

Table.9: Total harmonic distortion for load voltage without DVR and with DVR
Table. 9 shows the total harmonic distortion analysis, it is clear from this table that Fuzzy logic controller was unable to reduce the (THD) and make it within permissible limits in the case of $2^{\text {nd }}$ and $3^{\text {rd }}$ harmonics.

based on Fuzzy logic controller and Fuzzy neural controller

\begin{tabular}{|c|c|c|c|c|}
\hline \multirow{8}{*}{$\begin{array}{l}\text { Linear } \\
\text { Load }\end{array}$} & Power quality problem & $\begin{array}{l}\text { Without } \\
\text { DVR }\end{array}$ & $\begin{array}{l}\text { With DVR } \\
\text { based on } \\
\text { Fuzzy logic } \\
\text { controller }\end{array}$ & $\begin{array}{lr}\text { With } & \text { DVR } \\
\text { based } & \text { on } \\
\text { Fuzzy Neural } \\
\text { controller }\end{array}$ \\
\hline & $\begin{array}{l}\text { Single Line Fault } \\
\text { (unsymmetrical sag) }\end{array}$ & 1.743 & 1.31 & 1.31 \\
\hline & $\begin{array}{l}\text { Double Line Fault } \\
\text { (unsymmetrical sag) }\end{array}$ & 4.846 & 1.406 & 1.406 \\
\hline & $\begin{array}{l}\text { Three Phase Fault } \\
\text { (symmetrical sag) }\end{array}$ & 9.733 & 1.776 & 1.776 \\
\hline & Sag $(50 \%)$ & 2.554 & 1.39 & 2.55 \\
\hline & Swell $(50 \%)$ & 1.06 & 1 & 1.946 \\
\hline & $\begin{array}{l}\text { Sag with } 2^{\text {nd }} \text { and } 3^{\text {rd }} \\
\text { Harmonics }\end{array}$ & 15.24 & 5.84 & 2.256 \\
\hline & $\begin{array}{l}\text { Swell with } 2^{\text {nd }} \text { and } 3^{\text {rd }} \\
\text { Harmonics }\end{array}$ & 7.88 & 5.53 & 2.02 \\
\hline \multirow{2}{*}{$\begin{array}{l}\text { Non-Linear } \\
\text { Load }\end{array}$} & Sag $(50 \%)$ & 2.553 & 2.113 & 2.016 \\
\hline & Swell $(50 \%)$ & 1.256 & 1.823 & 1.443 \\
\hline
\end{tabular}

\section{CONCLUSIONS}

There is a tremendous advantage to use of neural methodologies to train fuzzy system. Embedding fuzzy notions into neural networks is an area of active research, and there are few well known or proven results. By using the ANFIS algorithm we can embed empirical information and expert into a fuzzy system. This greatly expands and enhances the range of applications of fuzzy systems. In this research paper, the modeling and simulation of DVR has been achieved by Fuzzy logic controller and Fuzzy neural controller. From the results obtained, The fuzzy neural based DVR effectively mitigates $2^{\text {nd }}$ order harmonic and $3^{\text {rd }}$ order harmonic associated with the voltage sags and swells and reduced the load harmonics from greater than $10 \%$ to less than $2 \%$. The proposed DVR also injects the appropriate voltage component to handles different fault conditions without any difficulties to keep load voltage constant and balanced under all power quality problems. From this work we can conclude that the applications whose one of its function is reduction the harmonics fuzzy neural be the appropriate option for such application.

\section{REFERENCES}

[1] A.Ghosh and G.Ledwich,"power quality enhancement using custom power devices".springer science and business media 2012

[2] N.G.Hingiram,"Introducing custom power" spectrum IEEE, vol.32, pp. 41-48, 1995.

[3] C.Sancaran, power quality. CRC press, 2001.

[4] Bollen, MHJ 2001, 'Understanding power quality problems-voltage sags and interruptions', IEEE Press series on power Engineering, NewYork.

[5] Ramachandaramurthy, VK, Fitzer, C, Arulampalam, A, Zhan, C, Barnes, M \& Jenkins, N 2002, 'Control of Battery supported dynamic voltage restorer'. IEEE Proceedings on Generation Transmission and Distribution, vol. 149, no. 5, pp. 533-542.

[6] Omar, R \& Rahim, NA 2012, ' Voltage unbalanced compensation using dynamic voltage restorer based on 
super capacitor ' , Electrical Power and Energy Systems, vol, 43 , no. 1, pp. 573-581.

[7] Wang, B \& Venkataramanan, G 2009, 'Dynamic voltage restorer utilizing a matrix converter and fly wheel energy storage' , IEEE Transactions on Industry Applications, vol . 45 , no. 1, pp. 1360- 1364.

[8] Amutha, N \& Kumar, BK 2013, 'Improvement fault ride-through capability of wind generation system using DVR', Electrical Power and Energy System , vol. 46, no. 1 , pp. 326-333.

[9] Ramasamy, M\& Thangavel, S2013 , 'Experimental verification of PV based Dynamic voltage Restorer (PVDVR) with significant energy conservation', Electrical Power and Energy System, vol. 49, no. 1, pp. 296-307.

[10] Newman, MJ, Holmes, DG, Nielsen, JG \& Blaabjerg, F 2005, 'Adynamic voltage restorer based on a four-leg voltage source converter, IET Generation, Transmission and Distribution, vol. 3, no. 5, pp. 437447

[11] Jimichi, T, Fujita, H \& Akagi, H 2008, 'An approach to eliminating DC magnetic flux from the series transformer of a dynamic voltage restorer ', IEEE Transactions on Industry Applications, vol. 44, no. 3, pp. 809-818.

[12] Teke, A 2011, 'Unified power quality conditioner: Design , simulation and experimental analysis', Ph.D. thesis, Cukarova University of Natural an Applied Sciences Jimichi, T, Fujita, H \& Akagi, H 2008, 'An approach to eliminating DC magnetic flux from the series transformer of a dynamic voltage restorer ', IEEE Transactions on Industry Applications, vol. 44, no. 3, pp. 809-818.

[13] http://www.mathworks.com/parktransformation.html

[14] S. Yasunobu and S. Miyamoto. Automatic train operation by predictive fuzzy control. In M. Sugeno , editor, Industrail Applications of fuzzy control, pages 118. North-Holland, Amsterdam, 1985.

[15] M. Sugeno. Current projects in fuzzy control. In Workshop on fuzzy Control System and Space Station Applications, pages 65-77, Huntington Beach, CA, 14-15 November 1990

[16] Tang H, Tan CK, Yi Z(2007) Neural network: computational models and applications. Stud Com Intell, vol 53. Springer, Berlin.

[17] http://www.mathworks.com/neural.html

[18] Jang JSR (1993) ANFIS: adaptive network-based fuzzy inference systems. IEEE Trans Sys Man Cybern 23:665685.

[19] Jang JS, Sun CT (1995) Neuro-fuzzy modeling and control. Proc IEEE 83(3):378-406 McCulloch WS, Pitts WH (1943) A logical calculus of the ideas immanent in nervous activity. Bull Math Biophys 5:115-133. 